\title{
LA UNIVERSIDAD EN EL CONSTITUCIONALISMO HISTÓRICO ESPAÑOL
}

MANUEL RAMÍREZ 


\title{
LA UNIVERSIDAD EN EL CONSTITUCIONALISMO HISTÓRICO ESPAÑOL
}

\author{
MANUEL RAMÍREZ \\ Catedrático de Derecho Político \\ Universidad de Zaragoza
}

Para evitar la sorpresa del lector que haya albergado alguna ilusión en lo extenso del título empleado, se hacen necesarios unos párrafos iniciales. Sencillamente, descartamos un análisis detallado del largo rosario de textos constitucionales que puebla todo nuestro siglo XIX. Cansaríamos en demasía a ese buen lector y, por demás, entraríamos en una serie de detalles de no excesiva importancia: textos en los que nada se dice sobre la Universidad, textos que repiten lo antes dicho, textos que se limitan a remitir a una ley posterior o, en fin, textos que cuanto dicen sobre el tema carecen del menor interés.

Por todo esto, nos limitamos aquí a reflexionar sobre los tres grandes momentos en que la Universidad, no siempre en concepción lineal, aparece y origina un punto de meditación, sin entrar, por lo de «histórico».

\section{PRIMER MOMENTO: LA CONSTITUCIÓN DE 1812}

El texto gaditano cita y regula expresamente nuestra institución. La lectura de los artículos 367, 368 y 369 nos adentran en el tema. Al amparo del Título IX que regulaba la Instrucción Pública y tras imponer que en todos los pueblos de la Monarquía se establecerían «escuelas de primeras letras», el art. 367, con redacción un tanto singular añade que «asimismo se arreglará y creará el número competente de Universidades y de otros establecimientos de instrucción que se juzguen para la enseñanza de todas las ciencias, literatura y bellas artes». A partir de este reconoci- 
miento constitucional, los artículos siguientes abundan en el detalle, que resulta sumamente sugestivo: el plan general de enseñanzas será uniforme en todo el reino, en todos los centros se deberá explicar la Constitución, como requisito insoslayable; la inspección de toda la enseñanza pública estará en manos de una Dirección general de estudios «compuesta de personas de conocida instrucción» emanada de la autoridad del Gobierno (Art. 369) y, en fin, las Cortes tendrán la última palabra para «arreglar cuanto pertenezca al importante objeto de la instrucción» (Art. 370). Como se verá, el Estado deja hacer pero siempre bajo su tutela y vigilancia.

Esta uniformidad y centralismo no puede sorprender ni un ápice si se piensa que los autores o constituyentes están situados en la línea de nuestros primeros liberales, sin duda con algún grado de lo ocurrido en Francia. Son los liberales de la primera hora que, ebrios de lo casi infinito de su poder, creen que pueden legislar con solemnidad y, sobre todo, «para siempre». Es lo que motiva que «los ciudadanos serán justos y benéficos», o con mayor riesgo, al afirmar que «la religión de la Nación española es y será perpetuamente la católica, apostólica, romana, única verdadera. La Nación la protege por leyes sabias y justas y prohíbe el ejercicio de cualquier otra» (Art. 12). La recepción de la Universidad, en nuestro primer texto constitucional no podría escapar de este halo que inspira en todo el texto. Y así, solemnidad, centralismo estatal y, por supuesto, siempre instrumento idóneo para enseñar y transmitir el contenido constitucional.

\section{SEGUNDO MOMENTO: EL PELIGROSO SILENCIO DE 1876}

Muy distinto matiz posee la Universidad en los años de la Restauración. Ante todo, sorprende que el texto de 1876 no dedique ni un solo artículo para mencionar, destacar su valor en el contenido del régimen y, acto seguido, fijar las líneas de su regulación. Por supuesto que no adoptamos la postura, defendida por algunos autores, de que la Universidad era también uno de los contenidos de la Constitución Interna sobre, como es sabido, Cánovas logró girar la vida política durante decenios. Aunque dicho contenido inicial (Rey y Cortes) se ampliara pronto de otros supuestos, como religión católica, lo cierto es que no llegó nunca a instituciones de menor tono como fuera la Universidad.

Ante este expreso silencio en un punto concreto, caben dos opciones. En primer lugar, remitirse a los derechos que en sus artículos iniciales proclama para todos los ciudadanos y en los que se hace hincapié en la religión Católica como religión del Estado: algo que originará un posterior debate al que ahora volveremos. Y, en segundo lugar y no sin alguna sorpresa, la gran delegación que sobre el tema hace el segundo párrafo del art. 12: «Todo español podrá fundar y sostener establecimientos 
de instrucción o de educación, con arreglo a las leyes» (¡curiosa revisión si en la Universidad estamos pensando!) Esta «omnipotencia creativa», se acomodará a una Ley especial, según se completa en este mismo art. 12: corresponde al Estado expedir los títulos profesionales y «establecer las condiciones de los que pretendan obtenerlos (...) Una ley especial determinará los deberes de los Profesores y las reglas a que ha de someterse la enseñanza en los establecimientos de instrucción pública costeados por el Estado, las provincias o los pueblos».

No deja de sorprender tanto la ausencia del término Universidad, cuanto la posterior exigencia de requisitos que, sin duda, la misma afectaba, con una remisión a una Ley posterior en asunto que nada tenía de baladí. La realidad sumaba a esta confusión que había centros ya existentes a los que se permitió que continuaran su existencia y ejercicio. Así las organizaciones obreras que siguieron su propia vía educativa, tales como la Escuela Nueva (de matiz socialista), o la Escuela Moderna de Ferrer (de carácter pro-anarquista).

Quizá la explicación a estas aparentes contradicciones está en el hecho de que el Estado abandonó en manos de quienes gozaban ya de poder y autonomía (la Iglesia, fundamentalmente) y, sobre todo, se mostraban ajenos a la idea del Estado liberal como denominador común.

El grave problema surge cuando Cánovas nombra a Orovio ministro de Fomento. A través de su persona pensaba Cánovas acentuar a una buena parte de la clientela que todavía era favorable al carlismo en arma. Orovio no tuvo escrúpulo al exigir al profesorado de todos los grados la promesa de atenerse a la doctrina católica vigente, prohibiendo cualquier tipo de crítica a tal doctrina: el atentado a la libertad de cátedra resultó evidente. Un grupo de profesores afectos al krausismo son separados de sus puestos y se lanzan a formar la Institución Libre de Enseñanza con inmediato éxito. La Universidad atravesó un penoso momento.

\section{TERCER MOMENTO: LA APARICIÓN DE LA AUTONOMÍA EN EL TEXTO DE 1931}

Dada la naturaleza de Estado Integral que la Segunda República Española adopta desde el primero de los artículo de su Constitución («La República constituye un Estado integral, compatible con la autonomía de los Municipios y las Regiones»), nada tiene de extraño que, por primera vez en nuestra historia política, se rompa la línea de exclusiva competencia estatal a la hora de reconocer y regular la Universidad.

Sin embargo, antes de reconocer la posibilidad de que alguna región autónoma se decida a crear su propia Universidad (no se olvide que, durante aquellos años la 
autonomía se concibió siempre como lo excepcional y no lo genérico, si bien el decurso de la historia podría haber tomado senderos bien distintos), en el art. 48 del texto se establecen algunos supuestos para todos los niveles educativos. Así, el carácter de funcionarios públicos que tendrán todos los enseñantes de cualquier nivel, reconocimiento y garantía del principio de libertad pública, la enseñanza será laica y se inspirará en «ideales de solidaridad humana», y «las Iglesias tienen el derecho, sujeto a inspección del Estado, de enseñar sus respectivas doctrinas en sus propios establecimientos», y la expedición de títulos académicos y profesionales corresponde exclusivamente al Estado, que establecerá las pruebas y requisitos necesarios para obtenerlos aun en los casos en que los certificados de estudios procedan de centros de enseñanza de las regiones autónomas (Art. 49).

Como puede verse, el texto constitucional fija con claridad los límites de las posibles ansias autonómicas que, en cualquier nivel educativo, pudieran aparecer. Y hay que esperar al art. 50 para encontrar ya una alusión directa a las posibles Universidades Autónomas, cuando se establece que «las regiones autónomas podrán organizar la enseñanza en sus lenguas respectivas, de acuerdo con las facultades que se concedan en los Estatutos». Aquí es donde aparece por vez primera la remisión a los Estatutos como fuentes legislativas. Y hay que señalar, aunque sea terreno ajeno al actual análisis, limitado a la esfera constitucional, que, al menos en este aspecto, el Estatuto de Cataluña de 1932, obra fundamentalmente del esfuerzo de Manuel Azaña, respetó cuidadosamente los citados límites fijados en los Artículos 48, 49 y 50 de la Constitución. Es en el art. 7 del Estatuto en el que se hace uso de la libertad para crear una Universidad Autónoma con aspiración de Universidad única. Tras estas citadas afirmaciones, acaso no sea disparatado afirmar el carácter mixto que esta experiencia tuvo.

Por lo demás, es sabido que el País Vasco no llegó a este fin, al tener que esperar a ser aprobado su Estatuto una vez estallado la Guerra civil, tras complicadas votaciones previas sobre todo por la resistencia de Álava. Y que el Estatuto de Galicia únicamente logró entrar en las Cortes, sin posterior tramitación. De esta forma, el precedente de Universidad Catalana es el único que quedará como válido en el recuento.

Title

The University in the historic spanish constitutionalism.

\section{Resumen}

El texto aborda algunos de los hitos esenciales en la evolución de la regulación de la Universidad en las constituciones históricas españolas. 


\section{Abstract}

The text deals with some of the milestones essential to the evolution of the regulation of the University in the Spanish historical constitutions.

\section{Palabras clave}

Universidad, constitucionalismo histórico español.

Key words

University, Spanish historical constitutionalism. 
